\title{
Integrating the Demographic and Health Surveys, IPUMS-I, and TerraPopulus to Explore Mortality and Health Outcomes at the District Level in Ghana, Malawi, and Tanzania
}

\author{
Rachel Sullivan Robinson ${ }^{1 *}$, Ann Meier $^{2}$, Jenny Trinitapoli ${ }^{3}$ and Joseph Svec ${ }^{4}$ \\ 1 School of International Service, American University, 4400 Massachusetts Avenue, NW, \\ Washington, DC 20016-8071; +1-202-885-1636; +1-202-885-2494 \\ robinson@american.edu \\ 2 Department of Sociology and Minnesota Population Center, University of Minnesota, Twin Cities \\ meierann@umn.edu \\ 3 Department of Sociology, Pennsylvania State University, State College \\ jennytrini@psu.edu \\ 4 Department of Sociology, University of Minnesota, Twin Cities \\ svecx006@umn.edu
}

\begin{abstract}
In this paper, we first show how the Demographic and Health Surveys (DHS) can be integrated with other data sources to expand the types of variables available for analysis of population and health outcomes. Second, we demonstrate one particular example of such integration by modelling the social, physical, and built environment determinants of health outcomes at the district level in Ghana, Malawi, and Tanzania. To do so, we created district-level measures of a number of variables from the DHS, and then merged them with district-level data from the IPUMS, an environmental data set called TerraPopulus, and other sources. We find that it is feasible to combine the DHS with other data sources, and that many health and environment indicators are heterogeneous within countries, justifying further analysis at low levels of geography and suggesting benefits to using such techniques to design fine-grained programmatic interventions.
\end{abstract}

Keywords: DHS; IPUMS; TerraPopulous; Spatial Analysis; Health

\section{Résumé}

Nous montrons d'abord comment les Enquêtes Démographiques et de Santé (EDS) peuvent être intégrés avec des autres sources de données pour créer des nouveaux types de variables pour l'analyse de la population et de la santé. Deuxièmement, nous modélisons les déterminants des résultats pour la santé de l'environnement social, physique, et construit au niveau du district au Ghana, au Malawi et en Tanzanie. Pour faire cela, nous avons utilisé l'EDS pour créer des mesures au niveau dudistrict, et les avons fusionnés avec les données de l'IPUMS, de TerraPopulus (que s'agit de l'environnement), et des autres sources. II est possible de combiner l'EDS avec les autres sources des données, et les indicateurs de santé et d'environnement sont hétérogènes au sein des pays. Cela justifie une analyse plus approfondie aux échelles géographiques plus locales et indique les avantages d'utiliser ces techniques pour concevoir des interventions programmatiques localisé.

Mots clé: EDS; IPUMS; TerraPopulous; Analyse Spatiale; Santé

\footnotetext{
${ }^{*}$ Corresponding author
} 


\section{Introduction}

The Demographic and Health Surveys (DHS) are the preeminent data source for studying a broad range of health outcomes across sub-Saharan Africa. One of the ways to enhance this rich data source is to combine it with other datasets in order to conduct spatially-based analyses, or to provide contextual variables for individual-level analyses. In this paper, we first demonstrate the feasibility of such integration by merging DHS data from Ghana, Malawi, and Tanzania-aggregated at the district level-with data from a variety of sources to create a data set that captures mortality and health outcomes (e.g., child mortality, infant mortality, and the proportion of children born underweight) and key indicators of the social, physical, and built environment, such as breastfeeding duration, rainfall, and access to water/sanitation. We then use these integrated data to carry out an exploratory spatial analysis of the relationship between the social, physical, and built environment and health and mortality outcomes.

We focus on sub-Saharan Africa-the region featuring the highest disease burden in the world, much of it due to HIV/AIDS, maternal causes, and diseases afflicting infants and children (Murray et al., 20I2). There are, however, outliers: healthy and unhealthy localities that can offer important insights for researchers and policy makers. Our focus on district-level data applies a distinguished insight from the fertility literature to the study of population health-that understanding differences within, not just between, countries will increase knowledge about the processes that produce good or poor health as well as the influences of local contexts on these processes.

Through our exploratory spatial analysis using DHS data integrated with other sources, we find that many health and environment indicators are heterogeneous within countries. Such heterogeneity justifies analysis at smaller geographic levels than are normally examined with DHS data and suggests that merged data such as ours may be used to design more effective and efficient interventions. In particular, knowing exactly how the social, physical, and built environments matter to health outcomes in specific localities can greatly aid health program design, given that social and built environmental factors may be changed, but physical factors can only be managed.

We summarize literature below as it relates to our application of merged DHS data to understand health and mortality outcomes at the district level. We then describe how we merged the DHS with other data sources, present the results of our exploratory spatial analysis, and finish with conclusions about integrating data sources and conducting spatial analyses.

\section{Literature Review and Theoretical \\ Framework}

A wealth of cross-national research on health inequalities focuses on nation states, asking why some have better population health than others (Lopez et al., 2006; Murray and Lopez, 1999; Firebaugh and Goesling, 2004; Caldwell, 1986; Kuhn, 20I0; Edwards, 20II). These studies find that with the exception of sub-Saharan Africa (Firebaugh and Goesling, 2004; Wilson, 200I), health inequality is declining on a global scale, leading to demographic convergence.

In sub-Saharan Africa, life expectancy declined in the 1990s (Timaeus and Jasseh, 2004). Coupled with the continent's faster-than-average rate of population growth, this arrested an otherwise positive global trend toward lower levels of health inequality. Despite these troubling trends, Kuhn (2010) recently showed that four of II countries with the best infant mortality trajectories over the past 25 years were in sub-Saharan Africa. So while the world's poor health is concentrated in the subcontinent, healthy pockets exist, warranting a thorough investigation of mortality and broader health outcomes.

Scholars increasingly recognize that withincountry variation in health accounts for most of world health inequality-substantially more than the oft discussed national differences (Pradhan et al., 2003). The literature on health inequality has followed the scholarship on income inequality, but with some very different conclusions: two-thirds of global health inequality exists within countries, while only one-quarter of global income inequality exists within countries (Firebaugh, 2000; Milanovic, 1999). Notably, Pradhan and colleagues (2003) report that four of the six countries with the greatest intracountry health inequality are in sub-Saharan AfricaChad, Zimbabwe, Nigeria, and Mali-but they neither discuss the spatial dimensions of withincountry variation nor specify the contexts that produce it.

Scholarship on health outcomes within countries relies heavily on individual-level data and situating individuals within their particular contexts via multilevel models. The exploratory spatial analysis we 
present is distinct in conceptualizing health primarily as an attribute of place - one that is not necessarily mediated by individual behaviour. Other scholars have taken a similar approach with promising results. Examining the influence of context on HIV outcomes, Feldacker et al. (20II) find that characteristics of place-specifically income inequality and distance from a health clinic within census enumeration areas-substantially and significantly affected individuals' likelihood of being HIV-positive. Notably, vulnerability to HIV infection was independent of individual indicators of risk behaviour such as multiple partnerships and condom use, especially for women. Similarly, scholars have noted that features of the physical environment like temperature (Patz et al., 2005) and rainfall (Maccini and Yang, 2009) are important determinants of health outcomes. These and similar micro-level studies represent an important shift in strategies to conceptualize and analyse population health-not exclusively as characteristics of individuals but also of places.

Our emphasis on place as a determinant of health reflects that of previous research on fertility. In particular, it hearkens back to insights generated by the European Fertility Project, which demonstrated how the diffusion of knowledge, ideas, and values within countries (i.e., rather than across national boundaries), facilitated fertility declines in Europe during the 19th century (Coale and Watkins, 1986). Further place-based insights from fertility research have come from sub-national studies in India (Guilmoto and Rajan, 200I), Brazil, and Mexico (Potter et al., 2010). We expect that a spatial perspective can yield similar insights into patterns of health and mortality.

\section{Data and Methods}

We merged existing data from the DHS, Integrated Public Use Microdata Series International (IPUMSI)," and a new data resource, Terra Populus (TerraPop).ii We then created and integrated new measures to proxy the presence of nongovernmental organizations (NGOs) and media coverage of health issues. In cases where the same variable existed in multiple data sets, we prioritized diversity in sources in order to demonstrate the potential for data integration. We focus on three countries-Ghana, Malawi, and Tanzania-as illustrative cases; our analyses are not comparative, but designed to show that the integration techniques are applicable across locales and that the conclusions of the exploratory spatial analysis hold regardless of context. We selected these countries as representative of the three major regions of the subcontinent (West, East, and Southern, respectively), capturing some of the diversity in social, physical, and built environments that characterizes subSaharan Africa.

The integration of data sources allows for analysis at the district level, arguably the ideal level for studying health outcomes because districts are small enough to reflect fine-grained heterogeneity in health, and also the administrative level at which most health programming is targeted. The DHS has provided data from nationally representative samples on population and health in over 90 countries for over 20 years. IPUMS-I, with a goal to "inventory, preserve, harmonize, and disseminate census microdata from around the world," provides a tremendous amount of basic demographic information (Minnesota Population Center, 2013a). TerraPop is a newly developing global population and environmental data resource that combines population data with environmental data such as land use, elevation and temperature (Minnesota Population Center, 20I3b).

In both IPUMS-I and TerraPop, district-level measures can be easily generated by aggregating micro-data, as all respondents are linked to the districts in which they reside. With DHS data, however, districts have to be generated by combining available geospatial data with district maps from Global Administrative Areas (GADM). Each DHS cluster is associated with latitude and longitudinal coordinates which can be merged with district boundaries as defined by the GADM database. Using ArcGIS, we matched the cluster codes with districts, ${ }^{\text {iv }}$ which then allowed us to produce reliable district-level aggregate measures from DHS micro-data (Burgert et al., 2012).

In the interest of harmonizing comparable measures across all data sources, we restricted the time frame for this analysis to 1998-2002. Publically available data from DHS (including geospatial data), IPUMS-I, and TerraPop are available at this time from all three countries. The end result is data for a total of 110 districts in Ghana, 28 in Malawi, and 134 in Tanzania.

Health Indicators We focus on three key infant and child health outcomes -infant mortality, child mortality, and low birth weight-using DHS data. We collapsed mortality measures by district as proportions of the sub-group by age. Proportion of infant deaths for each district is thus the number of those under 12 months who died in the year preceding the survey divided by the total number of 
those born in the previous 12 months, taken from the birth histories. The proportion of child deaths for each district is similarly the number of those between zero and five years old who died divided by the total number in that same age category. Finally, proportion low birth weight is the number of children in a district who were born below 2.5 kilograms, the World Health Organization cut-off for low birth weight, divided by the total number of children born.

Across the districts examined, approximately eight per cent of infants died during their first year. But $20 \%$ of districts experienced no infant deaths in the previous year, while in one district close to a third of children born in the previous year died. In terms of child mortality, a similar pattern emerges: $14 \%$ of districts experienced no child deaths, and the maximum was a third of children. The low birth weight variable has the highest percentage of zeroes (close to half), with a mean of three per cent and a maximum of slightly more than a fifth of babies.

The literature indicates that the factors relevant to infant and child mortality include fertility behaviour, infant feeding/nutrition, access to health services, environmental health conditions, and socioeconomic status (Rutstein, 2000; Mosley and Chen, 1984). The main predictors of low birth weight are malnutrition, smoking, and in the case of sub-Saharan Africa, malaria (Guyatt and Snow, 2004; Kramer, 1987). Because low birth weight is a major predictor of infant mortality (McCormick, 1985; Mosley and Chen, 1984) and because our independent variables include characteristics of the physical environment that closely correlate with malaria, we examine the same set of predictors for low birth weight as we do for infant and child mortality. Focusing on the characteristics of place, rather than individuals, we categorize the independent variables as pertaining to social, physical, or built environments.

Social Environment To capture the social environment, we use five measures. First, because of the relevance of contraception to birth spacing, overall fertility, and thus infant and child mortality (Cleland et al., 2012), we leverage DHS data to calculate the proportion of women in a district who have heard of family planning on the radio. On average, $50 \%$ of women in each district had heard a family planning message on the radio in the months preceding the survey. Second, because of the key role that breastfeeding plays in infant nutrition and mortality (Rutstein, 2000), we operationalized breastfeeding norms by calculating the average months of breastfeeding for the most recent, weaned child of DHS women, which was slightly more than 16 months on average. Third, as a proxy for socioeconomic status (Rutstein, 2000), we obtained from IPUMS-I the proportion of district residents who are literate. From self-reports, one is literate if he or she can read and write in any language, which has an average of $58 \%$.

Our fourth measure of the social environment reflects the potential of the media to raise awareness about health issues (Krieger et al., 2013), particularly before social programs fully address them (Hilliard et al., 2007). The media coverage of health issues is a measure of how frequently the written press mentions a particular district in conjunction with health outcomes. This variable is based on newspaper articles catalogued at AllAfrica.com, which contains articles from

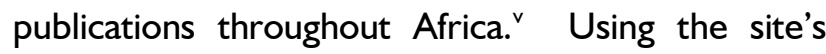
premium search engine, we identified all articles published between October 17, 1996 (the earliest date available) and December 3I, 200I (representing the end of our study period) that were tagged as relating to both (I) health and (2) the country in question (Ghana, Malawi, or Tanzania). The "health" category in AllAfrica.com covers a broad array of topics, ranging from HIV/AIDS to tuberculosis to maternal mortality. Then, using Provalis Research's WordStat program, we searched the body of each article for the mention of district and major city names. We coded this variable into four categories: zero mentions for a district; I mention; 2-5 mentions; and 6 or more mentions. On average, districts referenced in articles about health were mentioned 2.7 times, and slightly more than half of districts in our sample were not mentioned at all.

Our final measure of the social environment represents an element of access to care and is NGO presence by district. Building on the insight that countries with family planning NGOs have better health outcomes (Robinson, 20II) and that NGOs have been associated with positive health outcomes overall (Leonard, 2002; DeJong, 1991), we measured NGO presence at the district level, with a binary indicator of whether each district had an NGO operating within its borders in 200 I or earlier. To construct this variable, we used data from the NGO directory maintained by the Worldwide Association of Nongovernmental Organizations (WANGO). ${ }^{\text {vi }}$ Our measure covers all NGOs, and not just those that work in the area of health. Among NGOs listed in the WANGO directory, about half in 
Ghana and Tanzania, and only a quarter in Malawi, have founding dates. Among those NGOs with founding dates, in Ghana and Tanzania approximately half were founded prior to 2002, and in Malawi almost all were founded by that date. Overall, 10.5 per cent of districts had at least one NGO prior to 2002 (16.4\% in Ghana; $14.3 \%$ in Malawi; and $4.7 \%$ in Tanzania).

Physical Environment As characteristics of the physical environment, temperature (Patz et al., 2005) and rainfall (Maccini and Yang, 2009) are important determinants of health outcomes, particularly as they relate to malaria and low birth weight (Guyatt and Snow, 2004). To measure the physical environment, we leveraged data from TerraPop. We use three measures: average temperature, average rainfall, and average elevation. Temperature and average rainfall are based on records from 1950-2000. Month-by-month temperatures for each grid cell ( 12 temperature values per grid cell) capture seasonality, and the monthly values of each cell are then averaged to obtain the average annual temperature for the cell. The cells' annual average temperatures were averaged again across districts. The mean is 24.3 ${ }^{\circ} \mathrm{C}$. The rainfall measure represents the average total annual precipitation across the district in millimetres, and has an average of close to 120 centimetres. The average elevation for the districts is $58 \mathrm{I}$ meters.
Built Environment The ability to safely dispose of human waste and to keep living spaces free of contaminants are major determinants of infant and child mortality (Rutstein, 2000; Ikamari, 2013; Kibet, 2010). We use two measures to index related household and community infrastructure-the presence of a toilet in the home from IPUMS-I and the average number of minutes to a potable water source from DHS. The presence of a toilet in the home is a binary variable at the individual level that we indexed as a proportion of households in the district with a toilet. On average, approximately two thirds of district residents have a toilet in their home. Number of minutes to a potable water source is averaged over all DHS respondents in a district, and is 34 minutes on average (but ranging from five to 300 minutes).

We begin with descriptive spatial analysis based on maps of the three countries. We then present a bivariate analysis at the district level for Ghana, the country with the most complete data.

\section{Results}

Figure I shows pairs of choropleth maps for each of the three countries examined in the analysis. Panel a compares a feature of the social environment (literacy) with infant mortality in Ghana. Panel b compares a feature of the physical environment (elevation) with child mortality in Malawi. Panel c compares a feature of the built environment (toilet in the home) with low birth weight in Tanzania. These maps illustrate the heterogeneity in environmental and health variables within each of the three countries. 
Figure I. Spatial Analysis of Social, Physical, and Built Environments and Health Outcomes

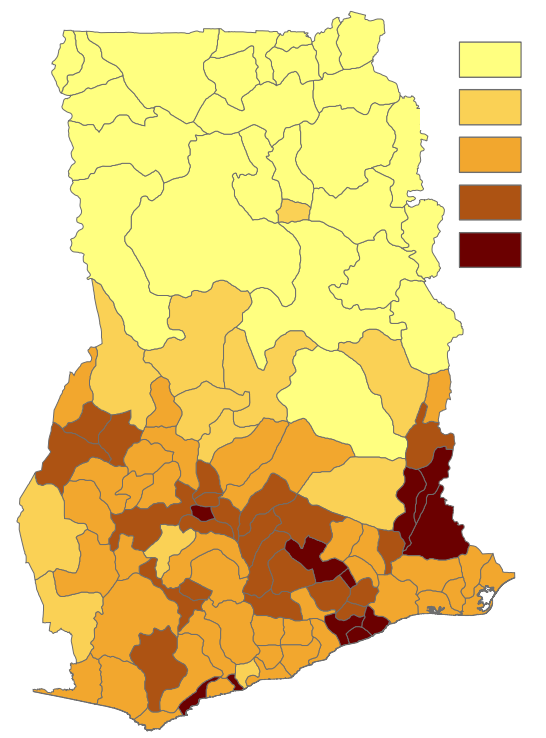
$0.13-0.30$
$0.31-0.46$
$0.47-0.59$
$0.60-0.68$
$0.69-0.85$

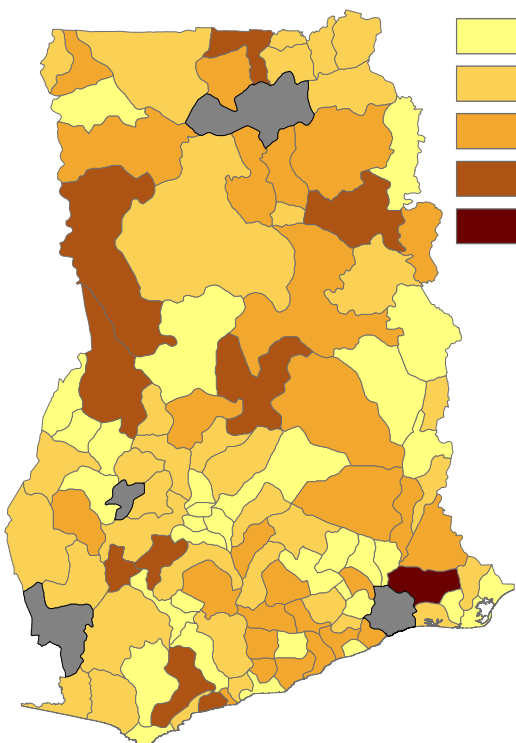

Panel I. Ghana

Proportion Literate (top) Infant Mortality (bottom)

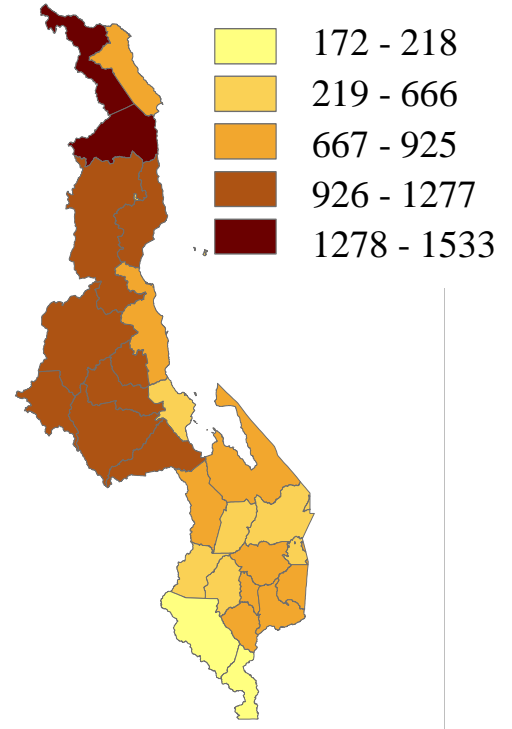

$0.00-0.01$

$0.02-0.07$

$0.08-0.13$

$0.14-0.25$

$0.26-0.50$

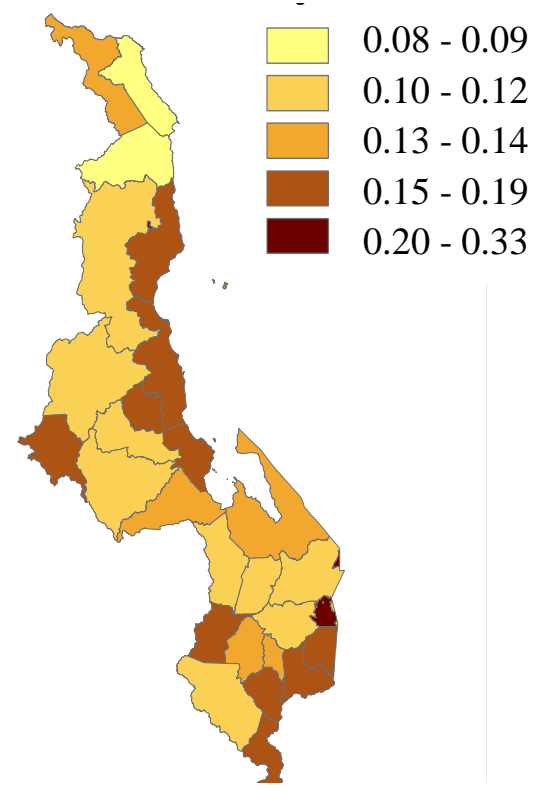

Panel 2. Malawi

Elevation, Meters (top)

Under-Five Mortality (bottom)

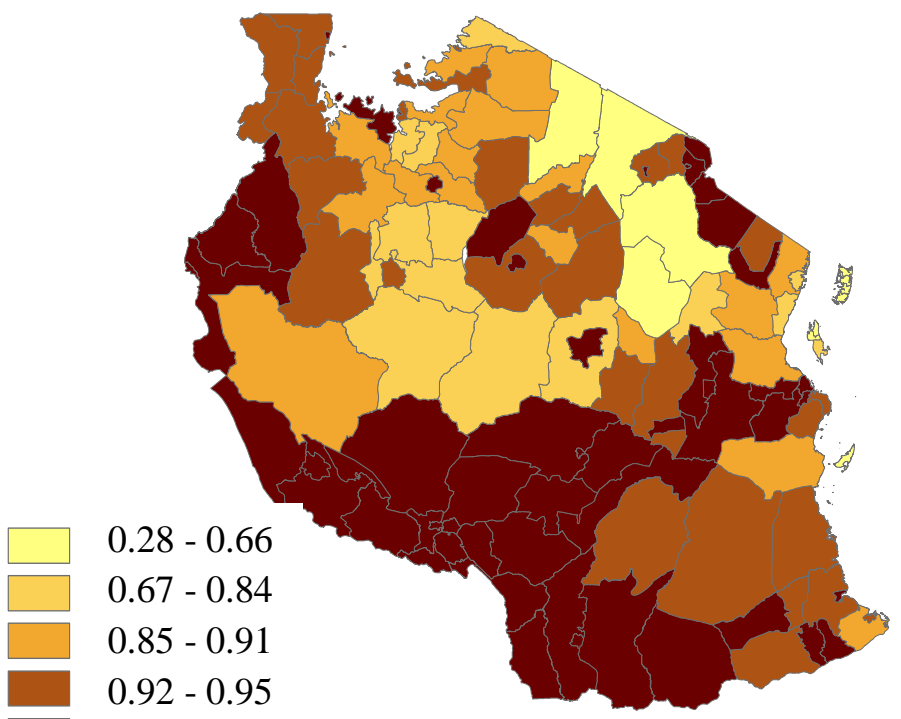

$0.96-0.99$

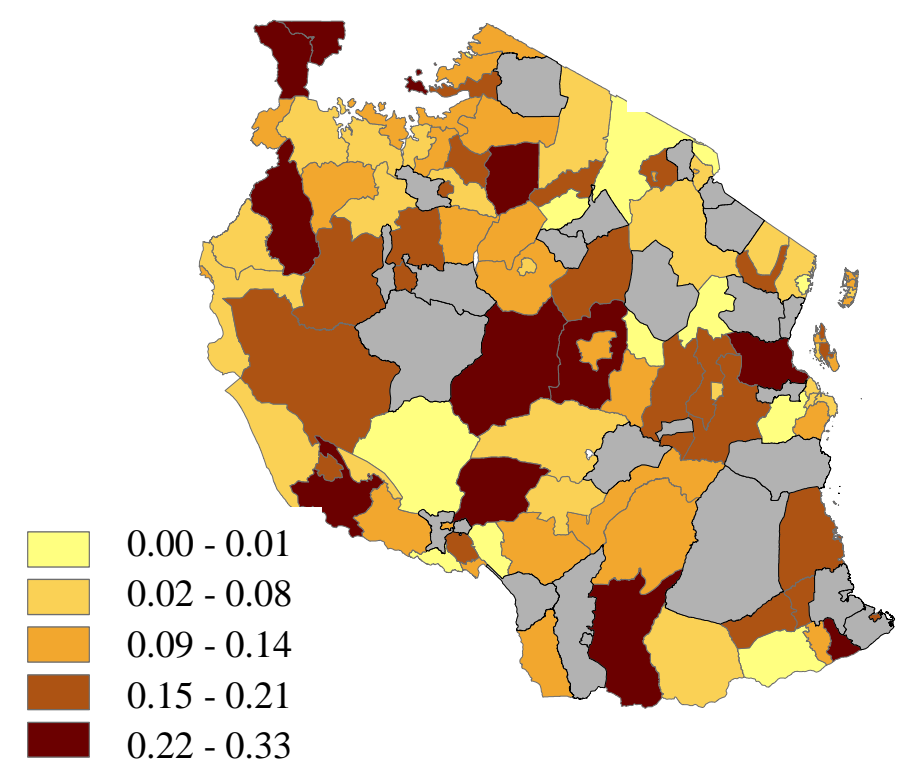

Panel 3. Tanzania

Toilet Ownership, Proportion (top) Low Birth Weight (bottom) 
Table I extends the comparisons made between the maps to show bivariate correlations (Pearson's $r$ ) between all independent variables and the three measures of infant and child mortality and health for Ghana.

Table I. Bivariate Correlations for District-Level Analysis of Health and Mortality Outcomes in Ghana

\begin{tabular}{|c|c|c|c|c|c|}
\hline & Source & Details & $\begin{array}{l}\text { Infant } \\
\text { Mortality }\end{array}$ & $\begin{array}{l}\text { Under- } \\
\text { Five } \\
\text { Mortality }\end{array}$ & $\begin{array}{l}\text { Low } \\
\text { Birth } \\
\text { Weight }\end{array}$ \\
\hline \multicolumn{6}{|l|}{ Social Environment } \\
\hline $\begin{array}{r}\text { Family planning } \\
\text { awareness }\end{array}$ & DHS & $\begin{array}{l}\text { Prop. of district women } \\
\text { heard family planning } \\
\text { message on radio }\end{array}$ & -0.15 & $-0.23^{*}$ & 0.13 \\
\hline $\begin{array}{r}\text { Breastfeeding } \\
\text { norms }\end{array}$ & DHS & $\begin{array}{l}\text { Average duration of } \\
\text { breastfeeding in district } \\
\text { (months) }\end{array}$ & 0.06 & 0.05 & 0.06 \\
\hline Literacy & IPUMS-I & $\begin{array}{l}\text { Proportion of district } \\
\text { residents who are literate }\end{array}$ & $-0.20^{*}$ & $-0.31^{* *}$ & 0.13 \\
\hline Media mentions & AllAfrica.com & $\begin{array}{l}\text { Number of health articles } \\
\text { mentioning district 1996- } \\
200 \text { I }\end{array}$ & -0.09 & -0.11 & $0.22^{*}$ \\
\hline Presence of NGO & WANGO & $\begin{array}{l}\text { At least one NGO in } \\
\text { district founded in } 200 \text { I or } \\
\text { earlier }\end{array}$ & -0.07 & -0.11 & 0.15 \\
\hline \multicolumn{6}{|l|}{$\begin{array}{l}\text { Physical } \\
\text { Environment }\end{array}$} \\
\hline Elevation & TerraPop & District average, in meters & $-0.20^{*}$ & $-0.16 \dagger$ & $0.19^{*}$ \\
\hline Temperature & TerraPop & $\begin{array}{l}\text { District average, in Celsius } \\
\times 10\end{array}$ & $0.22^{*}$ & $0.27^{* *}$ & -0.10 \\
\hline Rainfall & TerraPop & $\begin{array}{l}\text { District average, in } \\
\text { millimetres }\end{array}$ & -0.15 & $-0.17 \dagger$ & -0.06 \\
\hline \multicolumn{6}{|l|}{ Built Environment } \\
\hline Toilet in the home & IPUMS-I & $\begin{array}{l}\text { Proportion of people in } \\
\text { district with toilet in the } \\
\text { home }\end{array}$ & -0.10 & $-0.21^{*}$ & 0.01 \\
\hline Access to water & DHS & $\begin{array}{l}\text { Avg. minutes to potable } \\
\text { water source for district } \\
\text { residents }\end{array}$ & -0.03 & 0.10 & -0.12 \\
\hline
\end{tabular}

$+\mathrm{p}<0.10 ;$ * $^{\mathrm{p}}<0.05 ;$ ** $\mathrm{p}<0.01$; *** $\mathrm{p}<0.001$

Note: All dependent variables are from the DHS, $\mathrm{N}=107$. Details on measurement are included in the text.

\section{Discussion}

Panels $I$ and 2 of Figure I clearly show the expected, inverse relationships between variables. In Panel I, Ghana districts that are darker in the map on the top (literacy) are generally lighter in the map on the bottom (infant mortality). Similarly, in Panel 2. Malawi districts that are darker in the map on the top (elevation) are generally lighter in the map on the bottom (child mortality). The pattern in Panel 3, which considers the prevalence of underweight babies in Tanzania, is much harder to discern. A large proportion of the districts have no measured underweight babies, and there were 32 districts for which the number of DHS observations were insufficient for constructing reliable estimates. As a result, although some of the expected relationship is visible, it is certainly not as strong as that observed in the other two sets of maps.

More important than the inverse relationships between variables is the extensive heterogeneity observed across all three pairs of maps. In Ghana there is striking variation in both literacy and infant mortality. The same can be said of elevation and child mortality in Malawi and of sanitary 
infrastructure and low birth weight in Tanzania. Such heterogeneity in environment suggests that the same type of health program is unlikely to be equally effective across districts. It also shows that there are "positive deviants" to be explored further: districts with disadvantageous social, physical, or built environments that nonetheless perform well on health outcomes.

When comparing the relative strength of relationships between the three types of environment in Ghana and the three health outcomes (Table I), each type of environment matters, but the social and physical appear to matter more than the built. Specifically, literacy has a significant relationship with infant mortality, while both literacy and family planning awareness have significant relationships with child mortality-and in the expected directions. The relationship between media mentions and low birth weight is positive, suggesting that rather than helping to convey information, the media may report on worse-off districts precisely because of the (negative) health stories.

There are significant relationships between at least one of the physical environment variables and each of the three dependent variables. Elevation is the only physical environment variable that has a significant relationship across all three dependent variables, and is negatively associated with infant and child mortality, but positively associated with low birth weight. This relationship, as well as the marginally significant, negative relationship between rainfall and child mortality, are somewhat contrary to expectations, and may be the result of other peculiarities of the districts. If so, this suggests the potential of additional district-level measures to capture factors that could influence child health and mortality.

Finally, the only built environment variable with a significant relationship to the health outcomes we examine here is sanitation, which has the expected negative relationship with child mortality.

\section{Conclusions}

Our analysis makes two main contributions. First, we demonstrate the feasibility of combining DHS data with a variety of other sources, ranging from those that are readily available (IPUMS, TerraPop) to some requiring much greater prior manipulation (e.g., our media and NGO variables). Second, our exploratory spatial analysis demonstrates high levels of within-country heterogeneity in mortality and health outcomes, as well as high variability in the social, physical, and built environmental characteristics that drive those outcomes. The analysis indicates specifically that knowledge of family planning, literacy, and media mentions are the most important features of the social environment (that we were able to measure) that matter to infant and child health outcomes in Ghana. The relationships between the physical environment and infant and child health outcomes in Ghana are largely as expected, and equally strong to the social environment relationships. Variables representing the built environment in Ghana have the weakest relationship with health outcomes. Programming to improve infant and child health outcomes in Ghana should thus take into account both those factors that can be changed, even if with difficulty, such as the social and built environments, as well as those that can only be managed, such as the physical environment.

These analyses illustrate the potential utility of combining the abundance of variables in the DHS with yet other data sources in order to account for factors that may be critical for health outcomes but fall outside the scope of the DHS itself. Such an approach significantly expands the number of variables whose relationships with health outcomes can be tested. Where relevant, spatial approaches may be especially well-suited for aiding in the development of programs tailored specifically to these localities, thus leading to greater efficiencies. For example, the most innovative, and thus potentially effective, interventions are simply too expensive to implement across entire countries (e.g., antiretrovirals for HIV prevention). But, if the neediest districts could be identified, funding could be more accurately targeted.

Of course, our analyses are basic and primarily illustrative. In particular, because of small sample size, we were unable to explore as wide of an array of variables as would be necessary to design an effective intervention. Small sample size also prevented multivariate analysis. In addition, even though the DHS is nationally representative, not all districts have sufficient observations to generate reliable estimates, and the labour associated with creating variables like those measuring media coverage and NGO presence can become prohibitive. Nonetheless, these challenges hint at exciting areas for future research. In particular, because of the spatial and temporal reach of the DHS, our analysis could be expanded to include more countries as well as a longitudinal perspective, in addition to many more variables from the DHS 
and other sources. More advanced spatial analysis techniques, such as change detection, could be applied to the data, as could sophisticated multivariate modelling techniques. Many of the current challenges of using the DHS as with our example will be eased substantially with the Integrated Demographic and Health Series, a project to harmonize and integrate DHS surveys across countries and years. ${ }^{\text {vii }}$ Future research seeking to conduct comparative or longitudinal place-based analyses should look to this valuable resource.

\section{Acknowledgements}

We gratefully acknowledge the research assistance of Kate Tennis (American University) and support from the Minnesota Population Center (5R24HD04I023).

\section{References}

Burgert CR, Zachary B and Way A. (20I2) Response to "Problems of spatial linkage of a georeferenced Demographic and Health Survey (DHS) dataset to a population census: A case study of Egypt". Computers, Environment and Urban Systems 36: 626-627.

Caldwell JC. (1986) Routes to Low Mortality in Poor Countries. Population and Development Review 12: 17|-219.

Cleland J, Conde-Agudelo A, Peterson $\mathrm{H}$, et al. (2012) Contraception and health. The Lancet 380: 149-156.

Coale AJ and Watkins SC. (1986) The Decline of Fertility in Europe. Princeton, NJ: Princeton University Press.

Dejong J. (199I) Nongovernmental Organizations and Health Delivery in Sub-Saharan Africa. Policy, Research, and External Affairs Working Papers. Washington, DC: World Bank.

Edwards RD. (20II) Changes in World Inequality in Length of Life: 1970-2000. Population and Development Review 37: 499-528.

Feldacker C, Ennett ST and Speizer I. (20I I) It's not just who you are but where you live: An exploration of community influences on individual HIV status in rural Malawi. Social Science \& Medicine 72: 717-725.

Firebaugh G. (2000) The Trend in Between-Nation Income Inequality. Annual Review of Sociology 26: 323-339.

Firebaugh G and Goesling B. (2004) Accounting for the Recent Decline in Global Income Inequality. American Journal of Sociology I 10: 283-312.
Guilmoto CZ and Rajan SI. (200I) Spatial Patterns of Fertility Transition in Indian Districts. Population and Development Review 27: 713-738.

Guyatt HL and Snow RW. (2004) Impact of Malaria during Pregnancy on Low Birth Weight in SubSaharan Africa. Clinical Microbiology Reviews 17: 760-769.

Hilliard N, Jenkins R, Pashayan N, et al. (2007) Informal knowledge transfer in the period before formal health education programmes: case studies of mass media coverage of HIV and SIDS in England and Wales. BMC Public Health 7: 293.

Ikamari LD. (2013) Regional variation in neonatal and post-neonatal mortality in Kenya. African Population Studies 27: 14-24.

Kibet MK. (2010) Comparative study of infant and child mortality: The case of Kenya and South Africa. African Population Studies 24: I-25.

Kramer MS. (1987) Determinants of Low BirthWeight - Methodological Assessment and MetaAnalysis. Bulletin of the World Health Organization 65: 663-737.

Krieger JL, Katz ML, Eisenberg D, et al. (2013) Media coverage of cervical cancer and the HPV vaccine: implications for geographic health inequities. Health Expectations 16: el-el2.

Kuhn R. (2010) Routes to Low Mortality in Poor Countries Revisited. Population and Development Review 36: 655-692.

Leonard KL. (2002) When Both States and Markets Fail: Asymmetric Information and the Role of NGOs in African Health Care. International Review of Law and Economics 22: 61-80.

Lopez AD, Mathers CD, Ezzati M, et al. (2006) Global Burden of Disease and Risk Factors. Washington, DC: The World Bank and Oxford University Press.

Maccini S and Yang D. (2009) Under the Weather: Health, Schooling, and Economic Consequences of Early-Life Rainfall. American Economic Review 99: 1006-1026.

McCormick MC. (1985) The Contribution of Low Birth-Weight to Infant-Mortality and Childhood Morbidity. New England Journal of Medicine 312: 82-90.

Milanovic B. (1999) True World Income Distribution, 1988 and 1993 - First Calculations, Based on Household Surveys Alone. Policy Research Working Paper Series. Washington, DC: The World Bank.

Minnesota Population Center. (2013a) Integrated Public Use Microdata Series, International: 
Version 6.2 [Machine-readable database], Minneapolis: University of Minnesota.

Minnesota Population Center. (20I3b) Terra Populus: Beta Version [Machine-readable database], Minneapolis: University of Minnesota.

Mosley WH and Chen LC. (1984) An Analytical Framework for the Study of Child Survival in Developing Countries. Population and Development Review 10: 25-45.

Murray CJL and Lopez AD. (1999) On the Comparable Quantification of Health Risks: Lessons from the Global Burden of Disease Study. Epidemiology 10: 594-605.

Murray CJL, Vos T, Lozano R, et al. (20/2) Disability-adjusted life years (DALYs) for 291 diseases and injuries in 21 regions, 1990-2010: a systematic analysis for the Global Burden of Disease Study 2010. The Lancet 380: 2197-2223.

Patz JA, Campbell-Lendrum D, Holloway T, et al. (2005) Impact of regional climate change on human health. Nature 438: 310-317.

Potter JE, Schmertmann CP, Assunção RM, et al. (2010) Mapping the Timing, Pace, and Scale of the Fertility Transition in Brazil. Population and Development Review 36: 283-307.

Pradhan M, Sahn DE and Younger SD. (2003) Decomposing World Health Inequality. Journal of Health Economics 22: 27I-293.

Robinson R. (20II) From population to HIV: the organizational and structural determinants of HIV outcomes in sub-Saharan Africa. Journal of the International AIDS Society I4: I-I 3.
Rutstein SO. (2000) Factors associated with trends in infant and child mortality in developing countries during the 1990s. Bulletin of the World Health Organization 78: 1256- 270.

Timaeus IM and Jasseh M. (2004) Adult Mortality in Sub-Saharan Africa: Evidence from Demographic and Health Surveys. Demography 4I: 757-772.

Wilson C. (200I) On the Scale of Global Demographic Convergence 1950-2000. Population and Development Review 27: 155I7I.

\section{Authors' Contribution}

Robinson, Meier, and Trinitapoli all participated in the conceptualization, writing, and data analysis. Svec built the data set and made the maps.

\footnotetext{
' Downloaded from: http://www.measuredhs.com/Data/

ii Downloaded from:

https://international.ipums.org/international/

iii For more information, see:

http://www.terrapop.org/data. Thanks to TerraPop project manager Tracy Kugler for developing temperature, rainfall and elevation measures for use in this paper ahead of the TerraPop schedule.

iv A small percentage of clusters may be incorrectly matched to an adjacent district due to geo-displacement in the DHS data to ensure anonymity of the respondents.

${ }^{v}$ http://allafrica.com/search/advanced.html

vi http://www.wango.org

vii www.idhsdata.org
} 